\title{
Correction to: Enhancing the robustness of image watermarking against cropping attacks with dual watermarks
}

\author{
Ching-Sheng $\mathrm{Hsu}^{1} \cdot$ Shu-Fen $\mathrm{Tu}^{2}$ (D)
}

Published online: 10 January 2020

C) Springer Science+Business Media, LLC, part of Springer Nature 2020

\section{Correction to: Multimed Tools Appl (2019) \\ https://doi.org/10.1007/s11042-019-08367-6}

In the original publication, Equation 19 was incorrectly presented. The original article has been corrected.

Publisher's note Springer Nature remains neutral with regard to jurisdictional claims in published maps and institutional affiliations.

The online version of the original article can be found at https://doi.org/10.1007/s11042-019-08367-6

Shu-Fen Tu

dsf3@ulive.pccu.edu.tw

1 Department of Information Management, Ming Chuan University, No. 5, Deming Rd., GuishanDistrict, Taoyuan City 333, Taiwan

2 Department of Information Management, Chinese Culture University, No. 55, Huagang Rd., ShihlinDistrict, Taipei City 11114, Taiwan 